\title{
FUNGUS BALL PIELOURETERAL EN PACIENTES CON LITIASIS URINARIA. TRATAMIENTO CON URETERORRENOSCOPIA
}

\author{
J.P. BURGUÉS GASIÓN, J.M. ALAPONT ALACREU, F. OLIVER AMORÓS, \\ A. BENEDICTO REDÓN, F. BORONAT TORMO, J.F. JIMÉNEZ CRUZ
}

\author{
Servicio de Urología. Hospital Universitario "La Fe". Valencia.
}

Actas Urol Esp. 27 (1): 60-64, 2003

\begin{abstract}
RESUMEN
"FUNGUS BALL PIELOURETERAL EN PACIENTES CON LITIASIS URINARIA. TRATAMIENTO CON URETERORRENOSCOPIA"

INTRODUCCIÓN: C. albicans es el hongo que con mayor frecuencia produce infecciones oportunistas del tracto urinario. Cuando las hifas se aglutinan alrededor de un núcleo de tejido necrótico (necrosis papilar), hebras mucosas, restos de suturas quirúrgicas y/o material litiásico, se forma una pelota fúngica que puede obstruir cualquier tramo del tracto urinario.

CASOS CLÍNICOS: Presentamos dos pacientes formadores crónicos de cálculos que en ausencia de otros factores de riesgo para las infecciones fúngicas oportunistas, desarrollan fungus balls en el tracto urinario superior dilatado por una litiasis ureteral obstructiva. La paciente 1 tuvo afectación bilateral y en ningún momento hubo manifestaciones sistémicas. El tratamiento consistió en ureterorrenoscopia con extracción de las bolas fúngicas, derivación bilateral y anfotericina B sistémica y en irrigaciones tópicas. El paciente 2, en el contexto de una sepsis candidiásica, se trató con anfotericina B sistémica, desobstrucción mediante ureterorrenoscopia con extracción de un cálculo ureteral y de pelotas fúngicas, y colocación de catéter JJ y nefrostomía con irrigaciones de anfotericina B.

DISCUSIÓN: La litiasis urinaria constituye por sí sola un factor de riesgo para la infección fúngica del tracto urinario superior, en ausencia de otros factores favorecedores de las infecciones fúngicas oportunistas. El mecanismo por el cual el cálculo favorece el crecimiento de los hongos es, por un lado, la obstrucción pieloureteral con éstasis retrógrado y, por otro lado, la nucleación alrededor de una matriz de material cálcico sobre la que crecen, se agregan y se ramifican los micelios. La vía de infección es probablemente ascendente y puede complicarse con funguemia y sepsis. Los antimicóticos sistémicos, la derivación con catéteres ureterales o de nefrostomía que permitan irrigación local con antifúngicos, y las técnicas endourológicas, constituyen los tres pilares básicos del tratamiento. La ureterorrenoscopia juega aquí un papel importante al ser una técnica diagnóstica y al mismo tiempo terapéutica al permitir la desobstrucción litiásica y la limpieza de las masas fúngicas.
\end{abstract}

PALABRAS CLAVE: Litiasis urinaria. Fungus ball. Ureterorrenoscopia.

\section{ABSTRACT}

“PYELO-URETERAL FUNGUS BALL IN PATIENTS WITH URINARY LITHIASIS. URETERORRENOSCOPIC MANAGEMENT”

INTRODUCTION: C. albicans is the most frequent fungus causing opportunist infections of the urinary tract. Agglutination of necrotic tissue nucleus (papilar necrosis), mucosus debri and chirurgic or lithiasic debri, originates a fungus ball, which can obstruct the urinary tract at any level.

CLINICAL DATA: We present 2 patients with obstructive urinary lithiasis developing fungus ball in the dilated upper urinary tract. Patient 1 was bilaterally affected and never had systemic symptoms. Treatment consisted of uretherorrenoscope for removal of fungus ball, bilateral urinary diversion and anphotericine B irrigations and systemic. Patient 2 developed a candidemia and was treated with systemic liposomal anphotericine B, uretherorrenoscopy with removal of ureteric calculus and fungus ball, and placement of a double $\mathrm{J}$ catheter and nephrostomy tube for anphotericine $\mathrm{B}$ irrigation.

DISCUSSION: Urinary lithiasis is a risk factor for fungal infection of the upper urinary tract, provided there is no other predisponent factor for opportunistic fungal infections. Calculi facilitates fungal growth by means of obstruction and subsequent retrograde estasis and creating a nucleus for growth, aggregation and ramification of mycelium. The infection pathway is probably ascendent and may turn into fungemia and septicaemia. Systemic antimicotics, urinary diversion and local irrigations with antimicotics, and endourologic technics, are the three basic items in the treatment. Ureterorrenoscopy plays an important roll as a diagnostic and terapeutic tool as it may solve the obstruction and allows removal of fungus ball.

KEY WORDS: Urinary lithiasis. Fungus ball. Ureterorrenoscopy. 
$\mathrm{L}^{\mathrm{s}}$ as infecciones fúngicas del aparato urinario constituyen el 7,9\% de las infecciones nosocomiales ${ }^{1}$. Pueden ser primarias cuando afectan a individuos sanos, o más frecuentemente secundarias cuando se producen en sujetos con compromiso inmunitario (infecciones oportunistas). En el primer grupo tenemos la blastomicosis, coccidioidomicosis e histoplasmosis, y en el segundo encontramos la aspergilosis, criptococosis, candidiasis (la más frecuente), y la infección por Torulopsis glabrata. En los últimos años, el crecimiento de la población con alteraciones en la respuesta inmunitaria ha traído consigo un aumento en la incidencia de este tipo de infecciones en todas las edades ${ }^{2}$.

C. albicans es el hongo que con mayor frecuencia produce infecciones oportunistas del tracto urinario. Se trata de un organismo saprófito que podemos encontrar en genitales externos y uretra, y que en individuos con patologías predisponentes puede convertirse en patógeno: diabetes mellitus, antibioticoterapia prolongada de amplio espectro, terapia inmunosupresora (corticoides, radioterapia, quimioterapia...), tumores sólidos, hemopatías malignas, VIH, prótesis cardíacas, embarazo, recién nacidos prematuros, trasplantados, ADVP, uropatía obstructiva, catéteres urinarios y litiasis urinaria ${ }^{2,3}$.

Cuando se produce una infección fúngica del tracto urinario superior lo más habitual es que se manifieste como una pielonefritis aguda bacteriana, pero en raras ocasiones las pseudohifas o hifas pueden aglutinarse junto a restos de material necrótico, hebras mucosas y/o material litiásico, formando una pelota fúngica que puede obstruir el riñón o el uréter causando incluso en algunos casos fracaso renal ${ }^{4}$. Aunque el hongo más frecuentemente aislado en los casos de fungus ball del tracto urinario es Candida sp, se han descrito también pelotas fúngicas formadas por Penicillium sp, Aspergillus sp, Mucor sp y C. glabrata ${ }^{3}$.

Hoy en día, la extracción endoscópica y la irrigación tópica con antifúngicos han desplazado a la cirugía en el tratamiento de esta infrecuente patología. Presentamos 2 casos de fungus ball en pacientes con litiasis urinaria, sin otros factores de riesgo para infección fúngica, que son diagnosticados y tratados con ureterorrenoscopia.

\section{CASOS CLÍNICOS}

Caso 1: Mujer de 48 años con antecedente de múltiples cólicos nefríticos, el primero de los cuales lo presentó a los 30 años, tras un embarazo. Entre 1990 y 1998 la paciente presentó numerosos episodios de litiasis ureteral que fueron tratados mediante litotricia con láser y catéter JJ que se calcificaba rápidamente. El estudio metabólico demostró calciuria de 434 mg en 24 hr, con PTH normal y test de Pak evidenciando aumento de dicha calciuria tras la ingesta de calcio. Tras tratamiento con dieta restrictiva de calcio y aumento de la ingesta de líquidos, la calciuria descendió a $319 \mathrm{mg}$ en $24 \mathrm{hr}$ pero los episodios cólicos por litiasis ureteral persistieron. El análisis de los cálculos mostraba una mezcla de fosfato, oxalato y fosfato triple. Los pHs urinarios oscilaron entre 6 y 6,5, pero se descartó acidosis tubular renal.

En febrero de 1998 se remitió a Anatomía Patológica una formación blanquecina compuesta por material gelatinoso junto a concreciones cálcicas, que fue informada como colonias de hongos filamentosos entremezclados con depósitos de sales cálcicas (Fig. 1). El cultivo de ese material mostró el crecimiento de C. albicans, por lo que se inició tratamiento con fluconazol $200 \mathrm{mg} /$ día y alcalinización de la orina con citrato potásico. La candiduria persistió, así como los múltiples episodios de formación de estos agregados que obligaban a repetidas ureterorrenoscopias para su extracción.

En enero del 2000 se practicó nefrolitotomía percutánea bilateral con extracción de numerosas pelotas fúngicas caliciales (la Figura 2 muestra la UIV en ese momento). La imagen del nefroscopio flexible mostró la existencia de pequeños cálculos adheridos a las papilas, que parecían salir de los túbulos colectores y que se desprendian fácilmente al contacto con el nefroscopio. Se tomaron biopsias papilares, que fueron informadas como inflamación crónica inespecífica con incrustaciones cálcicas. Se practicaron irrigaciones con anfotericina $\mathrm{B}$ a través de las nefrostomías, se continuó tratamiento con fluconazol oral, alcalinización con citrato potásico y se añadieron tiazidas, pero los episodios cólicos continuaron.

Aunque el test de Brand para cistinuria había resultado negativo, se decidió cuantificar la cantidad de cistina en orina y se descubrió una cistinuria de baja intensidad (40 $\mathrm{mg}$ en $24 \mathrm{hr}$ ). Al 


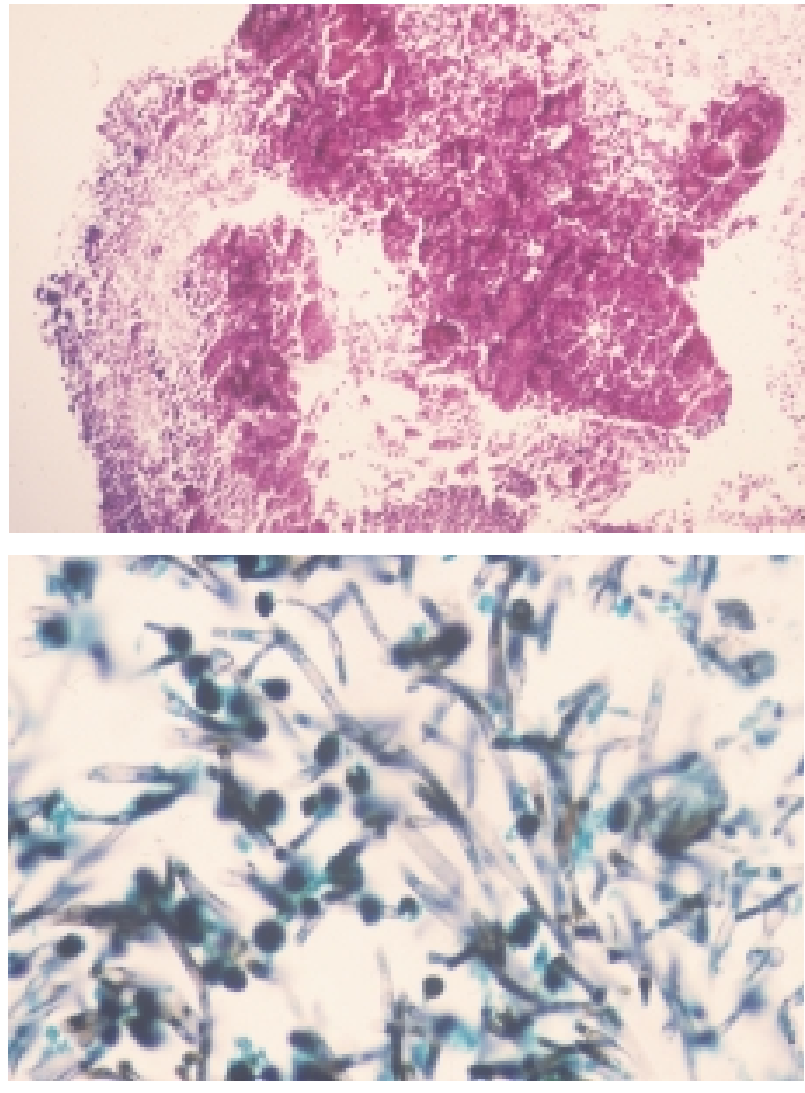

Figura 1: A. Tinción de hematoxilina-eosina: concreciones amorfas de calcio, basófilas, sin celularidad, que conforman un núcleo central; en periferia se observa una zona más disgregada, con formaciones filamentosas. B. Tinción de Grocot: pseudohifas no tabicadas, ramificadas en ángulo agudo; se aprecian también formas levaduriformes aisladas.

mismo tiempo, un nuevo fungibiograma demostró la existencia de una C. albicans resistente al fluconazol. Se decidió en este punto alcalinización urinaria con bicarbonato oral $15 \mathrm{gr} /$ día e inicio de tratamiento con anfotericina B intravenosa de forma continuada durante 14 días y posteriormente $1 \mathrm{vez}$ por semana durante 8 semanas. Con este tratamiento los episodios de fungus ball se repitieron tan sólo en 6 ocasiones más y fueron resueltos con ureterorrenoscopia y extracción con pinzas. Se practicó LEOC de calcificaciones renales residuales y, en los últimos 6 meses de seguimiento, la paciente no ha vuelto a presentar ningún episodio de dolor cólico. La UIV y la ecografía no muestran alteraciones en estos momentos.

Caso 2: Varón de 78 años con antecedentes de HTA, RTU prostática y cólicos nefríticos de repetición, que acudió a urgencias por dolor en fosa

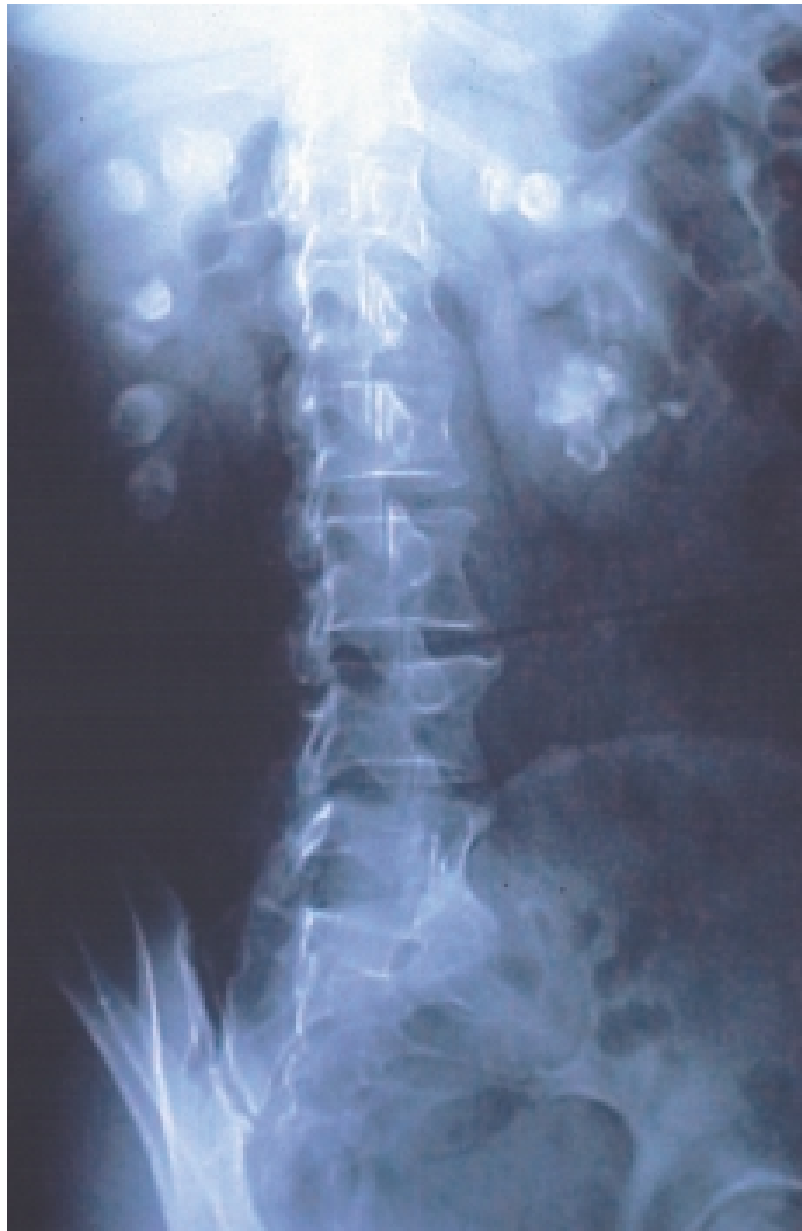

Figura 2: Urografia intravenosa: dilatación bilateral del sistema pielocalicial, con defectos de repleción caliciales y litiasis en cáliz inferior del riñón izquierdo.

renal izquierda y síndrome febril. La ecografía mostró ectasia grado II/IV en riñón izquierdo y en la radiografía simple de abdomen se observó una imagen cálcica en hemipelvis menor izquierda. El tratamiento inicial consistió en antibioticoterapia empírica de amplio espectro, ureterorrenoscopia con fragmentación y extracción del cálculo y de numerosas pelotas algodonosas de vejiga y uréter izquierdo (Fig. 3), más colocación de catéter JJ izquierdo. Conocidos el uro y hemocultivo positivos para C. albicans, se pautó anfotericina B liposomal sistémica y se decidió nefrostomía percutánea para irrigaciones con anfotericina B. Tras una semana el paciente mejoró clínicamente y el hemocultivo y cultivo de orina de la nefrostomía se negativizaron. La pielografía por la nefrostomía mostró un cálculo residual en uréter pélvico izquierdo, por lo que se practicó nueva 


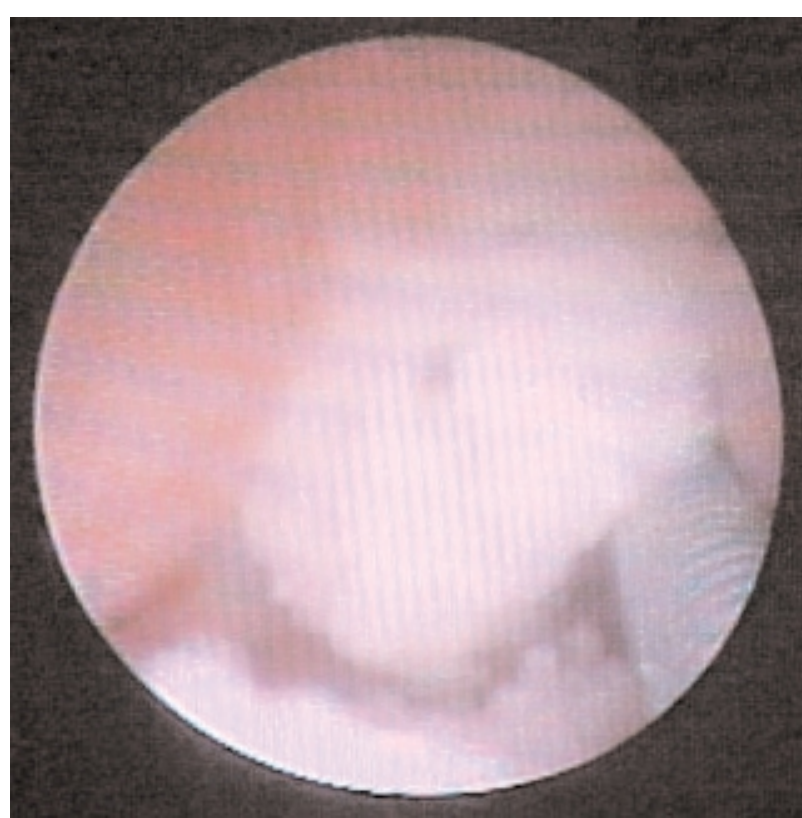

Figura 3: Ureterorrenoscopia: formación blanquecina, de consistencia algodonosa, que ocluye la luz ureteral. Guia de seguridad en la parte inferior derecha de la imagen.

ureterorrenoscopia con extracción del mismo, sin visualización en ese momento de pelotas fúngicas. La UIV de control posterior tras la retirada de los catéteres fue normal.

\section{DISCUSIÓN}

El fungus ball pieloureteral es una patología infrecuente, pero es importante tenerlo presente en el diagnóstico diferencial y conocer las peculiaridades de su correcto tratamiento. Habrá que sospecharlo ante alguna de las siguientes situaciones $^{5}$ :

1. Fiebre o febrícula recurrente en pacientes con factores de riesgo para infecciones fúngicas y que no cede con antibioticoterapia.

2. Presencia de funguria junto a obstrucción del tracto urinario.

3. Persistencia de funguria a pesar del tratamiento antifúngico $\mathrm{y}$

4. En el neonato ante la aparición súbita de HTA, masa renal o deterioro súbito de la función renal.

Tras el diagnóstico mediante urocultivos y técnicas de imagen, el manejo debe apoyarse en tres pilares fundamentales:

1. Medicación antifúngica IV, oral y/o en forma de irrigación.
2. Derivación urinaria mediante nefrostomía y/o catéter ureteral.

3. Técnicas endourológicas (nefroscopia o ureterorenoscopia) o cirugía abierta en último extremo ${ }^{5}$.

Nuestros 2 casos, a diferencia de otros descritos en la literatura ${ }^{3,6,7}$ en los que el diagnóstico se realizó radiológicamente demostrando defectos de replección en las pielografías y cultivos positivos para hongos, fueron hallazgos en la ureterorrenoscopia practicada para litotricia de cálculo ureteral. Ambos pacientes eran conocidos en nuestro Servicio por ser formadores crónicos de cálculos con múltiples sesiones de LEOC y manipulaciones endourológicas, por lo que la clínica compatible, la presencia de imágenes cálcicas en la radiografia simple (ausentes en placas anteriores) y la presencia de ectasia pielocalicial fueron suficientes para indicar una ureterorrenoscopia, sin necesidad de practicar urografias intravenosas. La ureterorrenoscopia permitió además del diagnóstico, la eliminación de la obstrucción ureteral, la extracción de las pelotas fúngicas, y la derivación interna mediante catéteres JJ.

La paciente 1 presentó múltiples episodios recurrentes de fungus ball ureteral que se resolvian temporalmente mediante ureterorrenoscopia y extracción con pinzas. Ni el tratamiento oral con fluconazol, ni la alcalinización de la orina con citrato potásico, ni las irrigaciones con anfotericina B consiguieron evitar las recurrencias. Sólo cuando se decidió tratamiento con anfotericina B liposomal intravenosa y alcalinización enérgica de la orina con $15 \mathrm{gr} /$ día de bicarbonato sódico oral, se consiguió la erradicación de la C. albicans y la desaparición de la formación continuada de cálculos. Nuestra experiencia, pone por tanto de manifiesto la necesidad del tratamiento parenteral para eliminar por completo la infección fúngica y resolver definitivamente el cuadro. El uso de anfotericina B intravenosa en esta paciente resultó determinante, incluso en ausencia de clínica sistémica y aún sabiendo que su excreción en orina es limitada.

Pensamos que la infección por C. albicans perpetuaba la formación de una orina ácida provocando la precipitación de material cálcico y colonias de hongos, formándose así las pelotas fúngicas. Es probable que los hongos quedaran acantonados 
en los túbulos colectores o incluso en el parénquima renal, siendo insuficientes las irrigaciones tópicas con anfotericina B para su erradicación. Mientras duró la infección, la precipitación del material cálcico fue masiva, formándose numerosos cálculos en muy poco tiempo. Cuando finalmente se logró controlar la infección fúngica con anfotericina B intravenosa y se inició un tratamiento alcalinizador enérgico, la paciente dejó de formar litiasis.

El paciente 2, además de irrigaciones locales a través de la nefrostomía, fue tratado con antifúngicos sistémicos de entrada dada la clínica séptica florida y el aislamiento de C. albicans en los hemocultivos. El tratamiento con antimicóticos tópicos y sistémicos, junto con la ureterorrenoscopia y extracción de las pelotas fúngicas fue rápidamente resolutivo en este segundo paciente.

Podemos concluir que la curación con garantías del fungus ball sólo se alcanza mediante un tratamiento combinado médico y endourológico, siendo necesarias la desobstrucción y extracción de las pelotas fúngicas con ureterorrenoscopia o nefroscopia según otros autores ${ }^{7}$, la derivación urinaria, y los antifúngicos intravenosos y aplicados localmente con irrigaciones periódicas. Nosotros pensamos que la ureterorrenoscopia juega un papel importante al permitir por un lado el diagnóstico mediante visualización directa y toma de muestras selectivas para cultivo, y al mismo tiempo por tratarse de una técnica terapéutica que permite la desobstrucción, la limpieza de las masas fúngicas, y la derivación del tracto urinario superior mediante colocación de un catéter ureteral.

Por último, queremos destacar que estos 2 casos de fungus ball confirman que la litiasis urinaria constituye por sí sola un factor de riesgo para la infección fúngica del tracto urinario superior, en ausencia de otros factores predisponentes ampliamente reconocidos como la diabetes melli- tus, la antibioticoterapia prolongada, los catéteres urinarios y los tratamientos o enfermedades crónicas que conllevan un compromiso inmunitario para el paciente. El mecanismo por el cual el cálculo favorece el crecimiento de los hongos es, por un lado, la obstrucción pieloureteral con éstasis retrógrado de la vía urinaria $\mathrm{y}$, por otro lado, la nucleación alrededor de una matriz de material cálcico sobre la que crecen, se agregan y se ramifican los micelios. La vía de infección en estos casos es ascendente, favorecida por los mecanismos citados, y puede complicarse con funguemia y sepsis.

\section{REFERENCIAS}

1. EDWARDS JE Jr.: Invasive candida infections-evolution of a fungal pathogen. $N$ Engl $J$ Med 1991; 324 (15): 1.060-1.062.

2. WISE GJ, SILVER DA.: Fungal infections of the genitourinary system. J Urol 1993; 149 (6): 1.377-1.388.

3. IRBY PB, STOLLER ML, McANINCH JW.: Fungal bezoars of the upper urinary tract. J Urol 1990; 143 (3): 447-451.

4. KHAN MY.: Anuria from candida pyelonephritis and obstructing fungal balls. Urology 1983; 21 (4): 421423.

5. BURGOS RODRÍGUEZ R, AGUAYO TRIANO M, PALANCA M.: Fungus ball. En: Leiva Galvis O, Resel Estévez L, editores. Patologías excepcionales en Urología. Madrid. Luzán-5, S.A. 1998: 417-439.

6. MENÉNDEZ LÓPEZ V, ELIA LOPEZ M, LLORENS MARTÍNEZ JF, GALÁN LLOPIS JA, DE NOVA SÁNCHEZ E, GARCÍA LÓPEZ F: Treatment of pelvis fungus ball with ureteral catheterization fluconazole and urine alkalinization. Actas Urol Esp 1999; 23 (2): 167-170.

7. NAVARRO SEBASTIÁN J, HIDALGO TOGORES L, CÁRCAMO VALOR P, JIMÉNEZ J, CÓZAR OLMO MJ, GARCÍA-MATRES MJ, et al.: Renal candidiasis: percutaneous endoscopic treatment of the pyeloureteral fungus-ball. Arch Esp Urol 1990; 43 (5): 543-549.

Dr. J.P. Burgués Gasión

Illes Balears, 105 - piso $\mathrm{K}$

07014 Palma de Mallorca

(Trabajo recibido el 24 julio de 2002) 